\title{
Tree is Life: uma aplicação no auxílio da resolução de conflitos entre arborização e equipamentos urbanos
}

\section{Savio Guedes Amaral ${ }^{1}$, Lizandro Pereira de Abreu $^{2}$,* e Felipe Gonçalves dos Santos ${ }^{1}$}

${ }^{1}$ Instituto Federal do Piauí. Curso de Graduação em Tecnologia de Análise e Desenvolvimento de Sistemas. Campus Corrente. Rua Projetada 06, no 380. Nova Corrente. Corrente-PI, Brasil (CEP 64980-000).

${ }^{2}$ Instituto Federal do Piauí. Campus Corrente. Rua Projetada 06, no 380 . Nova Corrente, Corrente-PI, Brasil (CEP 64.980-000). E-mail: lizandro.abreu@ifpi.edu.br.

Resumo. Apesar de todos os benefícios gerados pela arborização urbana (amenização do microclima, melhora na qualidade do ar, abrigo para fauna, redução da poluição sonora), quando tem seu planejamento mal elaborado, torna-se necessária a realização de constantes manutenções, pois ela pode causar diversos problemas na infraestrutura das cidades (sinalização de trânsito, redes de energia, rachaduras em muros e calçadas). Embasado nos problemas desencadeados pela falta de planejamento na arborização urbana, este trabalho objetiva propor a utilização de uma tecnologia auxiliar à população e aos órgãos competentes, na resolução destes conflitos de forma prática e eficiente. 0 estudo foi desenvolvido em três etapas e mostra a ferramenta Tree Is Life como método tecnológico na proposição de melhorias na arborização. A aplicação mostrou-se como um suporte de suma importância no auxílio da resolução dos conflitos existentes entre equipamentos urbanos e a arborização de logradouros públicos, além de apresentar diversas vantagens em relação à apps semelhantes.

Palavras-chave: Planejamento urbano; Usabilidade móbile; App.

Abstract. Tree is Life: An application to help resolve conflicts between urban afforestation and urban equipment. Despite all the benefits generated by urban afforestation (improvement of microclimate and air quality, shelter for fauna, reduction of noise pollution), when your planning is poorly prepared, it is necessary to carry out constant maintenance, as it can cause several problems in the city infrastructure (traffic signs, energy networks, cracks in walls and sidewalks). Based on the problems triggered by the lack of planning in urban afforestation, this work aims to propose the use of an auxiliary technology to the population and the competent managers, in the resolution of these conflicts in a practical and efficient way. The study was developed in three stages and shows the tool Tree Is Life as a technological method in
Recebido

$22 / 02 / 2021$

Aceito

$30 / 05 / 2021$

Disponível on line $31 / 05 / 2021$

Publicado

$31 / 08 / 2021$

Acesso aberto

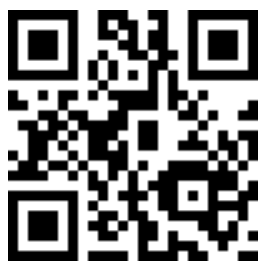

ORCID

D 0000-0001-9437-8669 Savio Guedes Amaral

(D) 0000-0001-6427-3356 Lizandro Pereira de Abreu

(D) 0000-0002-0323-8327 Felipe Gonçalves dos Santos

ISSN 2359-1412/RBGAS-2021-0018/2021/8/19/3/701

Rev. Bras. Gest. Amb. Sustent.

http://revista.ecogestaobrasil.net 
proposing improvements in afforestation. The application proved to be an extremely important support in helping to resolve conflicts between urban equipment and the afforestation of public places, in addition to presenting several advantages over similar apps.

Keywords: Urban planning; Mobile usability; App.

\section{Introdução}

O processo de urbanização tem desencadeado cada vez mais problemáticas ao meio ambiente decorrentes principalmente do aumento populacional. Consequentemente, tem sido necessário adotar determinadas medidas para tornar cada vez melhor os ambientes urbanos. Métodos como a arborização urbana são comumente usados nas cidades com a finalidade de melhorar as condições humanas e ambientais.

A arborização traz diversos benefícios para os locais onde é implantada, contribuindo para a saúde ambiental a partir da sua influência no bem estar do homem, em razão dos diversos benefícios que proporciona ao meio, que além de contribuir à amenização climática, embeleza pelo variado colorido que exibe, fornece abrigo e alimento à fauna, bem como proporcionar sombra e lazer nas praças, parques e jardins, ruas e avenidas (Lazzari et al., 2015; Lago et al., 2019; Oliveira et al., 2019).

Segundo a COPEL (2009) a arborização urbana como, vegetações que pertencem a todo perímetro urbano. É um dos recursos mais influentes no ecossistema das cidades. Basicamente, a arborização urbana é dividida em áreas verdes (parques, bosques, praças e jardinetes) e arborização de ruas (vias públicas).

Entretanto, se a implantação da arborização urbana não passar por um cauteloso processo de planejamento, aumenta consideravelmente a ocorrência de problemas associados a essas árvores. Trabalhos desenvolvidos em diversos municípios demonstram esses conflitos, a exemplo de Frederico Westphalen-RS (Lazzari et al., 2015), Formosa do Rio Preto-BA (Alves et al., 2019), Brejo Santo-CE (Moura et al., 2020), Icapuí-CE (Oliveira Júnior et al., 2020), Valença-BA (Silva Junior et al., 2020) e no Brasil (Pradella et al., 2020). A arborização urbana apresenta necessidade de manutenção pois algumas espécies perdem suas folhas, flores e frutos além de precisarem de podas, para remoção de galhos secos e sem vitalidade ou que estejam trazendo problemas urbanos. Mediante essas interferências provocadas por falta de planejamento na arborização urbana, o uso de tecnologias se torna de grande importância, visando a auxiliar na agilidade da manutenção e correção desses problemas.

Por meio de parcerias entre professores do Curso de Tecnologia em Gestão Ambiental e professores e alunos do Curso de Tecnologia em Análise e Desenvolvimento de Sistemas, do Instituto Federal do Piauí, Campus Corrente, visando à melhoria do ambiente dos municípios, dando ênfase às suas infraestruturas, foi proposto 0 desenvolvimento de uma aplicação que facilitasse a comunicação entre população e os órgãos responsáveis, servindo como intermédio entre eles, que tem como propósito realizar reclamações sobre as interferências causadas pela arborização na infraestrutura das cidades.

Várias pesquisas tiveram essa ideia de aproximar os cidadãos aos gestores com o intuito de facilitar uma gestão municipal compartilhada. Lucena (2019), implementou o software de governança "Reporte Cidadão", que auxilia o cidadão a relatar os problemas urbanos encontrados em seu dia a dia. Com a ajuda do aplicativo os gestores municipais poderão tomar providências adequadas, uma vez que as informações disponíveis no relato são precisas, reais e atualizadas. 0 software foi implementado com a linguagem de 
programação Java Script e com o framework Node.js. 0 resultado final apresentado foi uma aplicação híbrida, sendo acessada via web e em plataformas mobile.

A aplicação "Pelas Ruas", disponibilizada do Google Play, tem como principal objetivo enviar imagem e descrição do problema encontrado. É uma plataforma colaborativa em que os usuários discutem e compartilham problemas urbanos no Município de Porto Alegre e região, essa iniciativa foi realizada em conjunto pela Gaúcha, Zero Hora e RBSTV.

O aplicativo "Prefeitura 360", desenvolvido por Molina (2021), funciona com a apresentação de uma série de categorias para cada problema encontrado. Seu objetivo é relatar problemas urbanos diretamente para a prefeitura, enviando fotos, localização, descrição do problema encontrado, além da funcionalidade de responder pesquisas e acompanhar notícias da cidade.

Do mesmo modo como realizado por Amaral e Santos Lopes (2019) e Tanaka et al. (2020), esse artigo tem como objetivo apresentar uma ferramenta desenvolvida na forma de um software. Todavia, a que hora é proposta, auxilia os habitantes nas situações de interferências causadas pela arborização urbana, tendo como ênfase o bem estar tanto da população como do meio natural, tornando mais rápido e prático a comunicação entre a população e os órgãos responsáveis. Assim, proporcionando melhor precisão em sentido de localização e informação acerca do conflito provocado visando, principalmente, à manutenção desses ambientes.

\section{Metodologia}

Na primeira etapa de desenvolvimento do Tree is Life o projeto contou com os professores de informática e de gestão ambiental, que realizaram os levantamentos de quais seriam as principais interferências causada pela arborização urbana, tais elas: interferência de árvores em redes elétricas, rede telefônicas, iluminação pública, sinalização de trânsito, interferência causadas por raízes (calçadas, muros, ...), inclinação das árvores, e podas drásticas.

Na segunda etapa foram realizadas várias séries de levantamentos de requisitos, e o estudo de quais seriam as melhores ferramentas utilizadas para o desenvolvimento da aplicação, tendo em vista as tecnologias mais recentes, e nos conceitos apresentados em sala. E na terceira e última etapa foi a implementação do projeto, e no desenvolvimento do aplicativo em paralelo com website, onde foi hospedado na nuvem, juntamente com o banco de dados, o aplicativo foi desenvolvido tanto para Android, como IOS.

\section{Arquitetura e tecnologias}

O aplicativo conectará com a API para que os dados sejam salvos no banco de dados hospedado na nuvem, quando for solicitada uma reclamação. 0 controle dessas reclamações será feito pelo administrador do sistema, que ficará responsável por entrar em contato com os órgãos responsáveis. A Figura 1 relata a arquitetura e funcionamento do Tree is Life.

Para o desenvolvimento da aplicação foi utilizado um framework para dispositivos móveis denominado de Flutter. Integrado a um banco de dados distribuído hospedado na nuvem denominado como MySQL, que será acessado através de uma API pela aplicação mobile. 0 controle do sistema será feito pelo website. Para a implementação do mesmo, teve como base a linguagem de programação PHP. O framework Flutter foi desenvolvido pela Google e se trata de um kit de ferramentas de interface, onde fornece uma série de componentes visuais e funcionais para o desenvolvimento de aplicativos híbridos, pois com um único código e permitindo que seja compilado tanto para Android como IOS. 


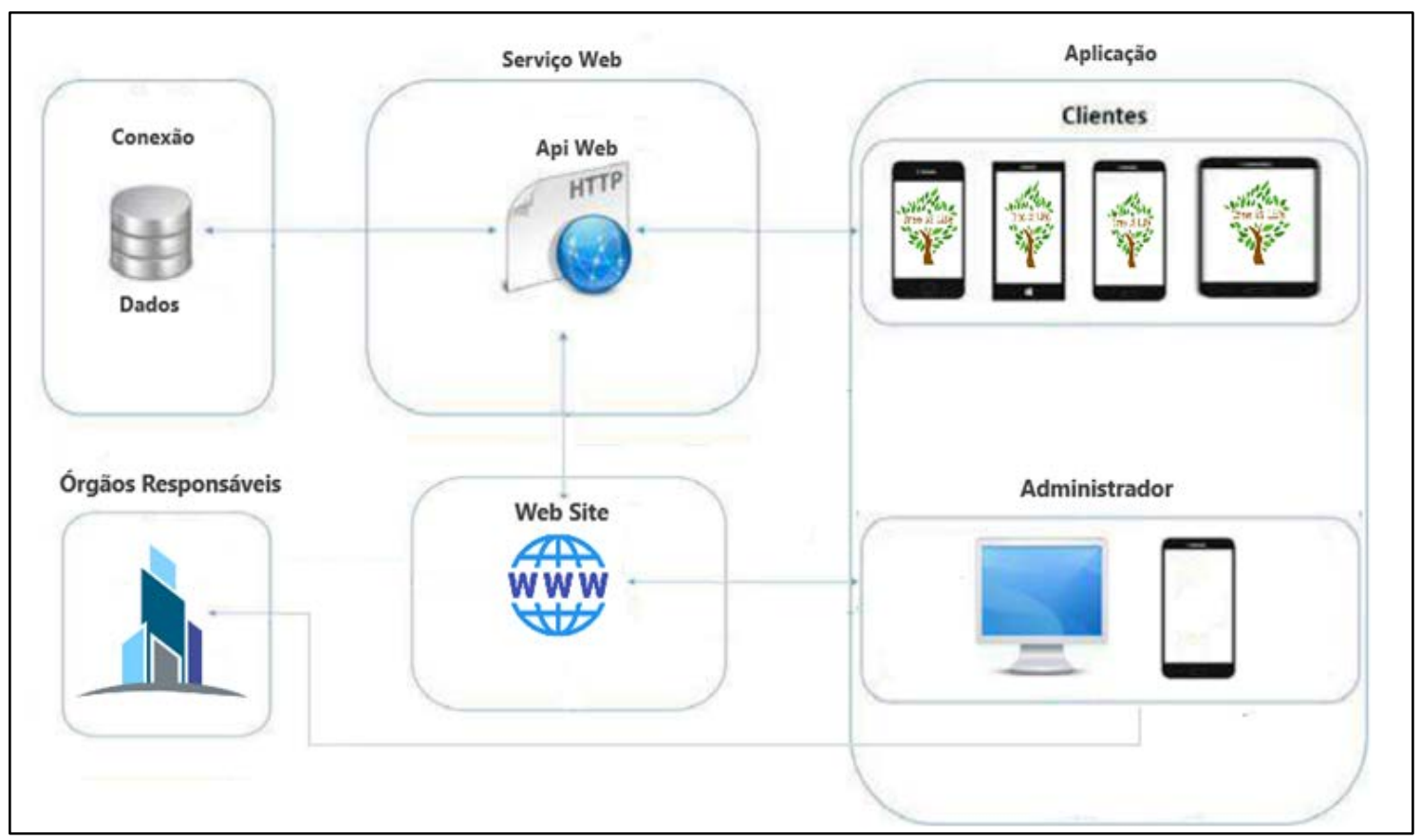

Figura 1. Arquitetura e funcionamento do Tree is Life.

O conceito de API é uma forma de integrar sistemas, possibilitando benefícios como a segurança dos dados, facilidade no intercâmbio entre informações com diferentes linguagens de programação e a monetização de acessos (Fernandes, 2018; Freitas e Ruschel, 2015).

O Flutter apresenta um intermediário (bridge) entre a UI e o dispositivo, ele se encontra na camada do UI (User Interface) e não chama os componentes nativos do SO, ele é desenhado exatamente em um canvas que aumenta a performance e fluidez a nível de um aplicativo desenvolvido exclusivamente nativo. Além do ganho com performance, o Flutter é uma tecnologia recente de fácil aprendizado e já possui alguns recursos sendo desenvolvidos, por esses motivos que ele foi escolhido ao invés do React Native. Apesar de o React Native ser também uma tecnologia recente, por ele não trabalhar na camada do UI (User Interface) e sim com chamada os componentes nativos do SO que ele não foi escolhido (Santos, 2018).

O MySQL é um sistema gerenciador de banco de dados relacional de código aberto usado na maioria das aplicações gratuitas para gerir suas bases de dados. O serviço utiliza a linguagem SQL (Structure Query Language), que é a linguagem padrão na indústria de banco de dados, para inserir, acessar e gerenciar o conteúdo armazenado num banco de dados (Malucelli et al., 2010; Pisa, 2012).

O PHP é uma linguagem de script open source de uso geral, muito utilizada, e especialmente adequada para o desenvolvimento web, que pode ser utilizada em conjunto com a linguagem de marcação de hipertexto (HTML), juntamente com javascript e css.

\section{As características da aplicação (Tree is Life)}

Esse aplicativo tem como principal característica a marcação de pontos geográficos no mapa, contendo as informações sobre as interferências causa pela a arborização na infraestrutura das cidades que são cadastrados pelos usuários, além disso, os pontos que já foram cadastrados poderão receber um aumento no seu número de 
reclamações (funcionando com o like do Instagram), quanto maior o número de reclamação mais prioridade ela possui.

\section{Mobile (Tree is Life Mobile)}

O aplicativo mobile é constituído por três abas de navegação intuitiva e de simples usabilidade facilitando o entendimento de usuários leigos. Na primeira aba da aplicação exibirá todos os pontos marcados por todos os usuários. A segunda é a aba da reclamação e a terceira é sobre o aplicativo (Figura 2).
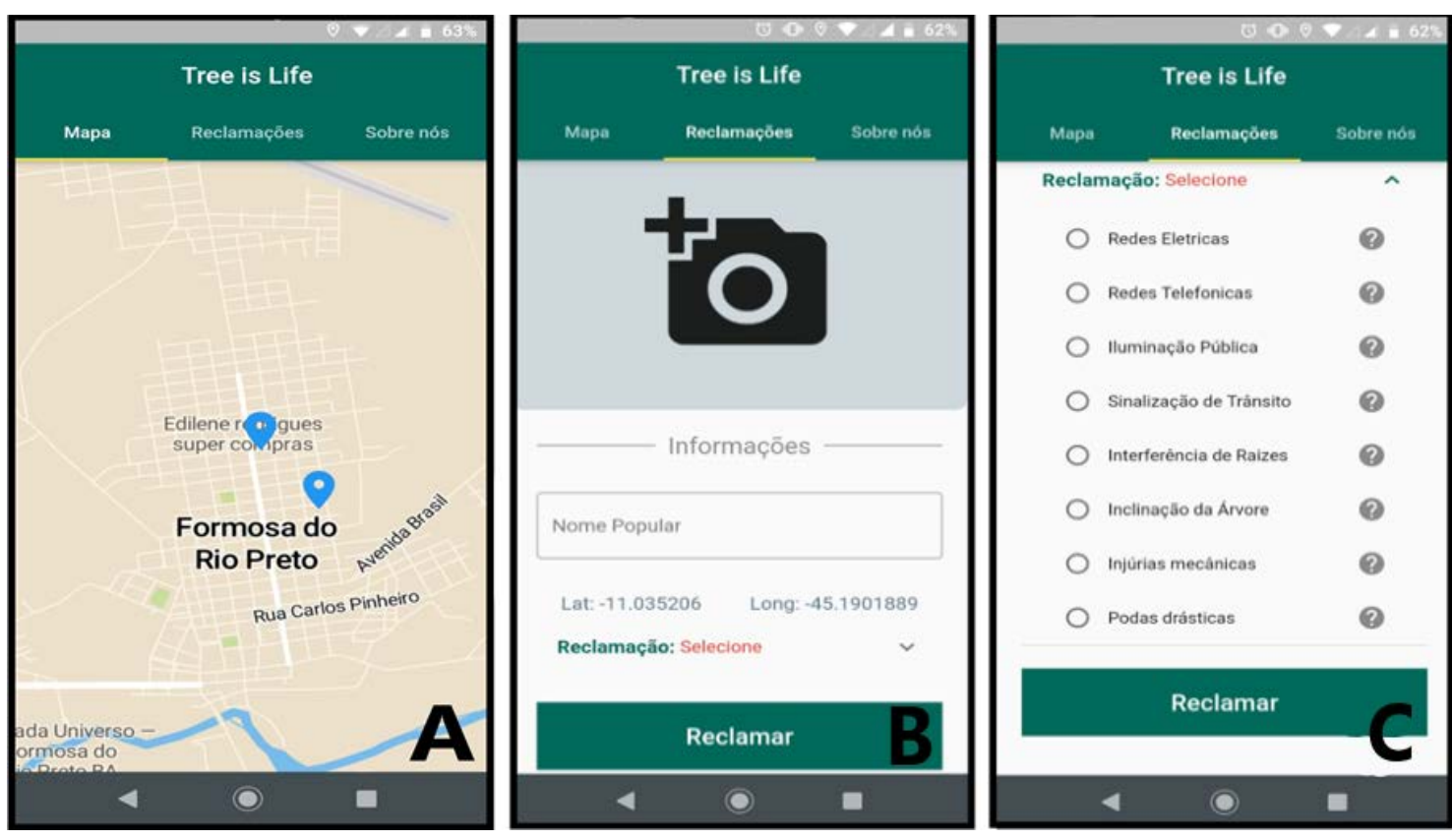

Figura 2. (A) Página inicial do aplicativo, onde será exibido todos os pontos que foram marcados pelos usuários do aplicativo. (B) Tela para efetuar uma nova reclamação. (C) Tipos de reclamações em que os problemas se encaixam.

A Figura 2A apresenta a página inicial do aplicativo, onde são exibidos todos os pontos que foram marcados pelos usuários. Na primeira aba ao clicar em um ponto marcado a aplicação exibirá os detalhes da reclamação, contendo as fotos que foram tiradas, quantidades de reclamações feitas pelos usuários, o tipo de reclamação e o nome da árvore caso o usuário tenha informado.

A Figura 2B retrata a tela para efetuar uma nova reclamação. Na segunda aba está relacionada às reclamações que serão cadastradas no sistema. Para cadastrar uma reclamação o usuário deverá tirar fotos do ocorrido, caso saiba, o nome (popular ou científico) da árvore pode ser relatado, a latitude e a longitude serão preenchidas automaticamente.

A Figura 2C mostra os tipos de reclamações disponíveis para serem relatados. Caso o usuário não saiba em qual tipo a interferência se enquadra, ao lado de cada opção possui o ícone de ajuda, onde terá exemplos e o seu conceito.

\section{0 website (Tree is Life Web)}

O sistema web desenvolvido com PHP servirá como controlador do sistema, onde o administrador será responsável por controlar todas as reclamações feitas pelo aplicativo. 
Para iniciar o website, o usuário deve possuir um navegador web e suas respectivas credenciais necessárias para acessá-lo. É obrigatória a identificação, como o nome do usuário e sua senha.

Ao efetuar o login no sistema o administrador poderá realizar todos os controles das reclamações que foram feitas pelos usuários. A Figura 3A mostra o mapa com os pontos marcados exibidos no website. Será listada no mapa os pontos geográficos marcados pelo aplicativo, onde foi definido de acordo com a quantidade de reclamações que cada ponto possuirá uma cor, tais como, verde (pequeno número de reclamações de 1 a 30), amarelo (número médio de reclamações de 31 a 70) e o vermelho (grande número de reclamação de 70 adiante), onde essas quantidades foram definidas pelo autor.
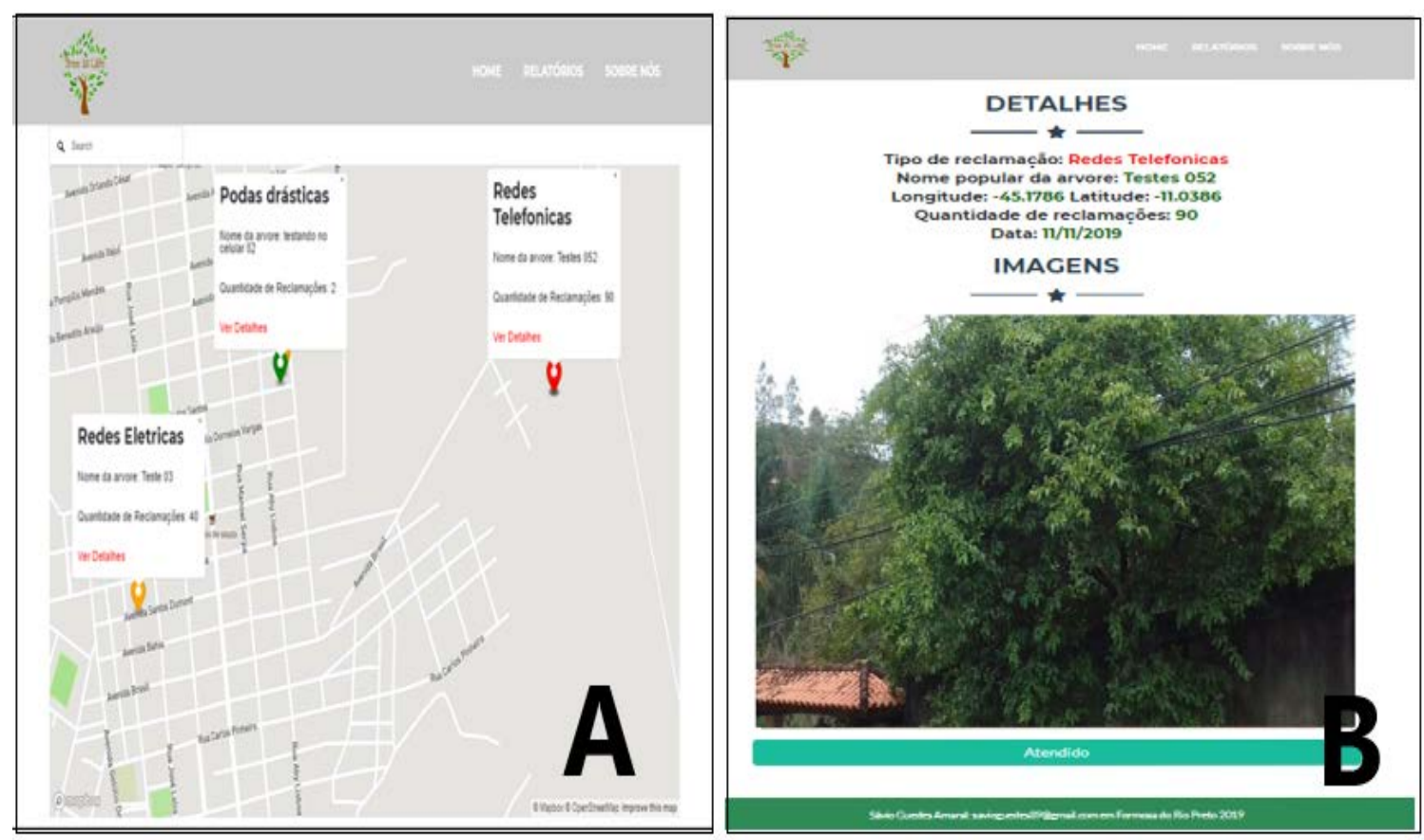

Figura 3. (A) Mapa com os pontos marcados exibidos no website do Tree is Life. (B) Detalhes dos problemas pressentem no website do Tree is Life.

Cada marcador geolocalizado possui detalhes, apresentando o tipo de reclamação, o nome popular da árvore, a quantidade de reclamações, e, as imagens de cada reclamação. A Figura 3B ilustra detalhes dos problemas presentes no website. Após o atendimento realizado pelos órgãos responsáveis, o administrador pode dar baixa do problema cadastrado no sistema. 0 administrador também poderá visualizar relatórios dos problemas que foram atendidos.

\section{Resultados e discussão}

Uma das grandes questões levantadas para a elaboração deste trabalho, além de fornecer dados para os órgãos responsáveis, era justamente fazer com que os cidadãos cuidassem tanto da infraestrutura como da flora das cidades. Com isso a aplicação se torna uma ferramenta indispensável para todos. Ademais, ainda pode ser aplicado nas áreas do 
meio ambiente, facilitando o estudo da arborização, pois a ferramenta apresenta todos os pontos onde se encontra alguma interferência causada por ela.

A fim de testar a aplicação foram realizados diversos teste de software, tais como: teste de usabilidade, testes funcionais e teste de segurança. Objetivando aprovar as funcionalidades propostas e encontrar os possíveis erros. Dentre as dificuldades observadas, a que se esteve mais presente no escopo da implementação foi na comunicação entre a aplicação e o website, exigindo correções por parte do autor para que assim pudesse chegar aos resultados desejados.

Para realizar os testes de usabilidade foi feito um questionário contendo 6 perguntas, que foram respondidos por 20 usuários do aplicativo, sendo elas: consigo mexer no sistema sem dificuldades? 0 sistema previne erros? 0 sistema tem uma interface agradável? de fácil utilização? As funções do sistema estão muito bem integradas? Você aprendeu a usar esse aplicativo rapidamente? Você se sente confiante ao usar o sistema? A Figura 4 mostra os resultados dos testes. Além dos testes, o aplicativo foi comparado com outros semelhantes.

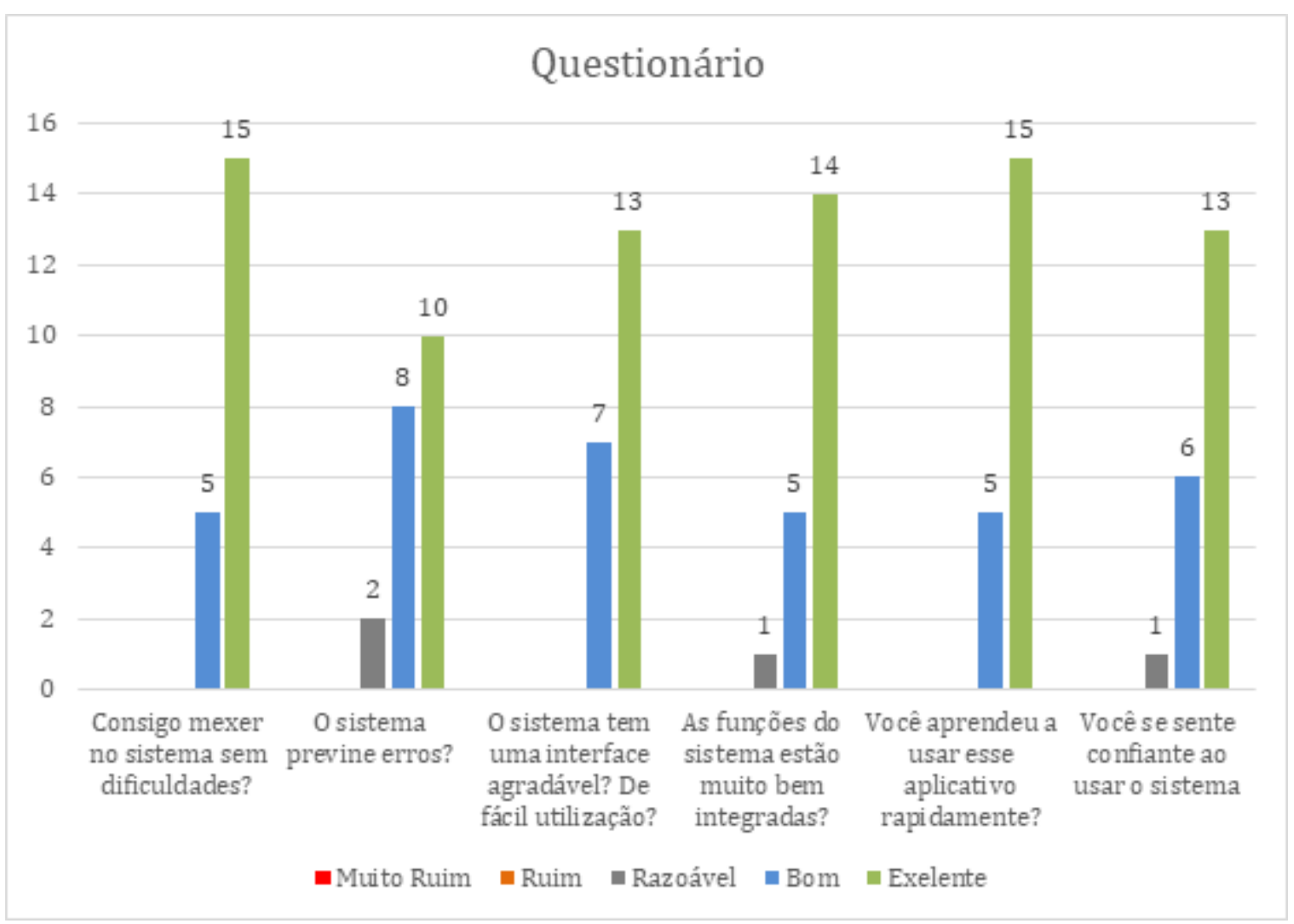

Figura 4. Questionamentos e respostas do teste de usabilidade.

A aplicação implementada por Lucena (2019), Reporte Cidadão, assemelha-se com aplicação desenvolvida nesse artigo. Eles se distinguem nas tecnologias utilizadas, tais como o framework como nas linguagens de programação. Mas uma das principais diferenças foi a área de estudo, pois, sua plataforma foca nos problemas urbanos, e a aplicação apresentada neste trabalho tem o objetivo evidenciar principalmente nos problemas causados pela arborização. 
A aplicação Pelas Ruas (Google Play, 2019), é uma plataforma onde os usuários compartilham imagem e o problema detectado, que serão debatidos pelos usuários de Porto Alegre e região, já o Tree is Life serve como intermediário entre os cidadãos e os órgãos responsáveis, que facilita a comunicação entre os mesmos.

0 aplicativo Prefeitura 360 (Google Play, 2019) possui algumas semelhanças com a aplicação desenvolvida nesse artigo, pois ele serve como o intermédio entre a população e a prefeitura, sobre os problemas encontrados no município. Entretanto, o Tree is Life engloba uma gama maior de órgãos responsáveis, abrangendo uma maior interação de organismos gestores e, não somente, se limitando apenas à prefeitura, além do mesmo focar apenas nos problemas causados pela arborização urbana na infraestrutura dos municípios.

A Tabela 1 demonstra as diferenças de recursos entre os aplicativos, mostra a diferença de recursos entre os aplicativos. Através dos levantamentos de funcionalidades ilustrados pode-se perceber que o aplicativo possui uma significativa relevância apresentando diversas vantagens, como multiplataformas permitindo ser utilizados por diferentes sistemas operacionais (Android, IOS) e garantindo a segurança de seus dados. A aplicação permite o acesso de múltiplos usuários, ou seja, vários adeptos do aplicativo podem utilizar o mesmo dispositivo para efetuar sua respectiva reclamação. Mesmo que o dispositivo não esteja devidamente conectado a uma rede de internet.

Tabela 1. Diferença de recursos entre os aplicativos.

\begin{tabular}{|l|c|c|c|c|}
\hline Funcionalidade & Reporte Cidadão & Pelas Ruas & Prefeitura 360 & Tree is Life \\
\hline Multiplataformas & Sim & Não & Não & Sim \\
\hline Segurança dos dados & Sim & Sim & Sim & Sim \\
\hline Múltiplos usuários & Não & Não & Não & Sim \\
\hline Reportar offline & Não & Não & Não & Sim \\
\hline
\end{tabular}

\section{Conclusões}

Percebemos que a arborização urbana no Brasil tem sido uma preocupação constante dos ambientalistas, uma vez observados as vantagens dessa para a sociedade. Com técnica e conhecimento específicos e tecnologia é possível trazer muitos benefícios para a comunidade que recebe em suas ruas, praças e avenidas um projeto de arborização urbana.

O aplicativo Tree is Life realiza reclamações de interferências causadas pela arborização nas pequenas e grandes metrópoles, mostra-se de fundamental importância na preservação das infraestruturas dos municípios. Após diversos testes realizados no Município de Formosa do Rio Preto-BA, foi comprovado a eficiência do sistema, chegando à conclusão de que o protótipo atende todas as funcionalidades planejadas na etapa inicial de criação.

Para trabalhos futuros, almeja-se implementar algumas funcionalidades com o intuito de facilitar a interação do usuário, como a comunicação direta com os órgãos responsáveis sem possuir um intermédio (administrador) entre eles. Além de realização de mais outros testes de software, como a realização dos testes de performance, testes de carga e estresse, e teste de estabilidade, a fim de deixar a ferramenta cada vez mais agradável ao uso. 


\section{Referências}

Alves, E. R. A.; Gavião, R. N. M.; Oliveira, G. L.; Nogueira, Y. S.; Abreu, L. P. Análise qualiquantitativa da arborização da Avenida Getúlio Vargas em Formosa do Rio Preto, Bahia. Revista da Sociedade Brasileira de Arborização Urbana, v. 11, v. 14, n. 3, p. 68-80, 2019. https://doi.org/10.5380/revsbau.v14i3.66772

Amaral, L. D.; Santos Lopes, M. S. Aplicativo móvel para ensino de programação utilizando laboratório remoto. Brazilian Journal of Development, v. 5, n. 12, p. 31702-31713, 2019. https://doi.org/10.34117/bjdv5n12-258

COPEL - Companhia Paranaense de Energia. A arborização urbana. 2009. Disponível em: <https://www.copel.com/hpcopel/guia_arb/a_arborizacao_urbana2.html>. Acesso em: 14 mar. 2020.

Fernandes, A. O que é API? Entenda de uma maneira simples. 2018. Disponível em: $<$ https://vertigo.com.br/o-que-e-api-entenda-de-uma-maneira-simples/>. Acesso em: 5 dez. 2020.

Freitas, M. R.; Ruschel, R. C. Validação de aplicativo comercial visando à incorporação da realidade aumentada a um modelo de avaliação pós-ocupação. Ambiente Construído, v. 15, n. 2, p. 97-112, 2015. https://doi.org/10.1590/s1678-86212015000200016

Google Play. Pelas Ruas. 2019. Disponível em: <https://play.google.com/store/apps/ details?id=br.com.gruporbs.pelasruas\&hl=pt_BR >. Acesso em: 18 nov. 2019.

Google Play. Prefeitura 360. 2019. Disponível em: <https:/play.google.com/store/apps/ details?id=com.caique.molina.prefeitura360\&hl=pt_BR>. Acesso em: 18 nov. 2019.

Lago, L. S.; Parlandim, L. S.; Reis, L. O.; Pereira, B. C.; Abreu, L. P. Análise quali-quantitativa da arborização de um condomínio horizontal na Cidade de Corrente - Piauí (Brasil). Revista Brasileira de Meio Ambiente, v. 7, n. 2, p. 29-39, 2019. https://doi.org/10.5281/ zenodo.3524787

Lazzari, L.; Georgin, J; Camponogara, A.; Maggioni, J. H; Oliveira, G. A.; Rosa, A. L. D. Diagnóstico da arborização urbana da Rua Arthur Milani na Cidade de Frederico Westphalen-RS. Revista Eletrônica em Gestão, Educação e Tecnologia Ambiental, v. 19, n. 3, p. 13-24, 2015. Disponível em: https://doi.org/105902/2236117017027

Lucena, L. B. Reporte Cidadão: um aplicativo híbrido para o relato e acompanhamento de problemas urbanos. Natal: Universidade do Estado do Rio Grande do Norte, 2019. (Monografia de graduação).

Malucelli, A.; Otemaier, K. R.; Bonnet, M.; Cubas, M. R.; Garcia, T. R. Sistema de informação para apoio à Sistematização da Assistência de Enfermagem. Revista Brasileira de Enfermagem, v. 63, n. 4, p. 629-636, 2010. Disponível em: https://doi.org/10.1590/ S0034-71672010000400020

Molina, C. Prefeitura 360. 2021. Disponível em: <http://prefeitura360.com.br/web>. Acesso em: 24 maio 2021.

Moura, J. S.; Pereira, A. C. M.; Santos, J. S.; Santana, S. H. M.; Silva, M. A. M.; Ferreira, W. N. Inventário florístico e percepção da população sobre a arborização urbana na Cidade de Brejo Santo, Ceará. Brazilian Journal of Development, v. 6, n. 10, p. 75773-75792, 2020. https://doi.org/10.34117/bjdv6n10-124 
Oliveira Júnior, F. V. L.; Nascimento, C. M.; Ferreira, E. S.; Soares, K. A.; Bezerra, L. F. L.; Oliveira, C. E. A.; Silva, P. R. A.; Cunha, M. L. Diagnóstico quantitativo e qualitativo da arborização de uma praça pública e de um mirante no Município de Icapuí-CE. Brazilian Journal of Development, v. 6, n. 8, p. 58645-58653, 2020. https://doi.org/10.34117/ bjdv6n8-321

Oliveira, M. R. G.; Castro, V. L. C.; Vieira, C. F.; Maciel, C. A.; Abreu, L. P. Análise qualiquantitativa da arborização da Avenida Getúlio Lustosa Nogueira, Cristalândia - Piauí (Brasil). Revista Brasileira de Meio Ambiente, v. 7, n. 2, p. 10-18, 2019. https://doi.org/ 10.5281/zenodo.3524799

Pisa, P. 0 que é e como usar o MySQL? 2012. Disponível em: <https://www.techtudo.com.br/artigos/noticia/2012/04/o-que-e-e-como-usar-omysql.html >. Acesso em: 16 ago. 2020.

Pradella, M. M.; Thies, C. L. O.; Souza, D. M. V.; Silva, T. F. Árvores x fachadas: de inimigos a aliados. Brazilian Journal of Development, v. 6, n. 8, p. 54716-54726, 2020. https://doi.org/10.34117/bjdv6n8-039

Santos, L. P. Desempenho de aplicações móveis utilizando implementação nativa ou frameworks multiplataformas. Recife: Universidade Federal de Pernambuco, 2018. (Monografia de graduação).

Silva Junior, A. S.; Freitas, R. M. O.; Matias, M. I. A. S.; Lucena, E. A. R. M. Levantamento de espécies arbóreas em vias públicas do Município de Valença - Bahia. Brazilian Journal of Development, v. 6, n. 12, p. 93958-93974, 2020. https://doi.org/10.34117/bjdv6n12-019

Tanaka, A. H. A.; Lima Mera, W. Y. W.; Silva, A. O.; Silva, A. O.; Melo, D. M.; Viégas, I. J. M.; Silva, D. A. S.; Silva Júnior, A. M. G. Fertiup! Aplicativo de recomendações de adubação e calagem para plantas medicinais. Brazilian Journal of Development, v. 6, n. 1, p. 430-440, 2020. https://doi.org/10.34117/bjdv6n1-029

Informação da Licença: Este é um artigo Open Access distribuído sob os termos da Licença Creative Commons Attribution, que permite uso irrestrito, distribuição e reprodução em qualquer meio, desde que a obra original seja devidamente citada. 